\title{
BMJ Open Behavioural activation versus mindfulness-based guided self-help treatment administered through a smartphone application: a randomised controlled trial
}

\author{
Kien Hoa Ly, ${ }^{1}$ Anna Trüschel, ${ }^{1}$ Linnea Jarl, ${ }^{1}$ Susanna Magnusson, ${ }^{1}$ Tove Windahl, ${ }^{1}$ \\ Robert Johansson, ${ }^{1}$ Per Carlbring, ${ }^{2}$ Gerhard Andersson ${ }^{1,3}$
}

To cite: Ly KH, Trüschel A, Jarl L, et al. Behavioural activation versus mindfulness-based guided self-help treatment administered through a smartphone application: a randomised controlled trial. BMJ Open 2014;4:e003440. doi:10.1136/bmjopen-2013003440

- Prepublication history for this paper is available online. To view these files please visit the journal online (http://dx.doi.org/10.1136/ bmjopen-2013-003440).

Received 20 June 2013 Revised 4 December 2013 Accepted 5 December 2013

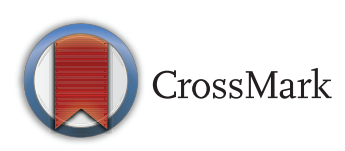

\footnotetext{
${ }^{1}$ Department of Behavioural Sciences and Learning, Linköping University, Linköping, Sweden 2Department of Psychology, Stockholm University, Stockholm, Sweden ${ }^{3}$ Department of Clinical Neuroscience, Center for Psychiatry Research, Karolinska Institutet, Stockholm, Sweden

Correspondence to Kien Hoa Ly; kien.hoa.ly@liu.se
}

\section{ABSTRACT}

Objectives: Evaluating and comparing the effectiveness of two smartphone-delivered treatments: one based on behavioural activation (BA) and other on mindfulness.

Design: Parallel randomised controlled, open, trial. Participants were allocated using an online randomisation tool, handled by an independent person who was separate from the staff conducting the study.

Setting: General community, with recruitment nationally through mass media and advertisements.

Participants: 40 participants diagnosed with major depressive disorder received a BA treatment, and 41 participants received a mindfulness treatment. 9 participants were lost at the post-treatment. Intervention: BA: An 8-week long behaviour programme administered via a smartphone application. Mindfulness: An 8-week long mindfulness programme, administered via a smartphone application.

Main outcome measures: The Beck Depression Inventory-II (BDI-II) and the nine-item Patient Health Questionnaire Depression Scale (PHQ-9).

Results: 81 participants were randomised (mean age 36.0 years $(S D=10.8))$ and analysed. Results showed no significant interaction effects of group and time on any of the outcome measures either from pretreatment to post-treatment or from pretreatment to the 6-month follow-up. Subgroup analyses showed that the BA treatment was more effective than the mindfulness treatment among participants with higher initial severity of depression from pretreatment to the 6-month follow-up (PHQ-9: $F(1,362.1)=5.2, p<0.05)$. In contrast, the mindfulness treatment worked better than the BA treatment among participants with lower initial severity from pretreatment to the 6 -month follow-up (PHQ-9: $F(1,69.3)=7.7, p<0.01)$; BDI-II: $(F(1,53.60)=6.25, p<0.05)$.

Conclusions: The two interventions did not differ significantly from one another. For participants with higher severity of depression, the treatment based on

\section{Strengths and limitations of this study}

- This is one of the first to perform a randomised controlled trial using smartphone applications.

- It did not control for the different components separately, so we cannot determine which parts of the treatments were effective.

- Despite the limitations, the results might indicate that the smartphone format used in this study could work well for a depressed population.

BA was superior to the treatment based on mindfulness. For participants with lower initial severity, the treatment based on mindfulness worked significantly better than the treatment based on BA. Trial registration: Clinical Trials NCT01463020.

\section{BACKGROUND}

Major depressive disorder (MDD) is a major health problem, which causes significant detrimental effects on the individual's quality of life and generates enormous costs for society. ${ }^{1} 2$ Several forms of psychotherapy have been found to be effective in the treatment of MDD. ${ }^{3}$ For example, behavioural activation (BA) has a strong empirical basis. ${ }^{4} \mathrm{BA}$ is an established psychological treatment derived from learning theory. It is aimed at increasing adequate behaviours and learning about the relations between behaviour and mood. The efficacy of BA for treating MDD has been established in a number of studies over the past four decades. ${ }^{5}$ Moreover, a dismantling study showed that BA could be as effective as the full cognitive behaviour therapy (CBT) treatment package. ${ }^{6}$ Moreover, in a later 
randomised controlled trial, $\mathrm{BA}$ was found to be as effective as antidepressant medication. ${ }^{7}$

It is also well established that guided self-help interventions, administered through the Internet, can have positive effects on symptoms of depression. ${ }^{8-10}$ An increasing number of studies show that this treatment format can be as effective as face-to-face treatment for mild-to-moderate MDD and anxiety disorders. ${ }^{9}$ Guided treatments distributed digitally have provided a way to reach a larger number of patients in a manner that in most cases requires less therapist time than face-to-face psychotherapy, but with similar clinical outcome. ${ }^{11}$ There are, however, to our knowledge no controlled trial of an Internet-delivered intervention based solely on BA, and no study using smartphones for the delivery of BA, even if studies are being conducted on smartphone-administered $\mathrm{CBT}^{12}{ }^{12}$ for example, in the treatment of MDD. ${ }^{13}$

Like BA, mindfulness is often used as a component in multicomponent treatment packages, such as mindfulness-based cognitive therapy $\left(\mathrm{MBCT}^{14}\right)$, dialectical behaviour therapy, ${ }^{15}$ and acceptance and commitment therapy. ${ }^{16}$ Studies have shown a significant negative correlation between mindfulness and depression, ${ }^{17}{ }^{18}$ meaning that more mindfulness practice is associated with lower levels of depression. Moreover, a meta-analysis based on 39 studies of mindfulness for depression and anxiety showed a moderate effect size of Hedges' $g=0.59$ for improving mood symptoms. ${ }^{19}$ The analysis also showed that mindfulness was effective for individuals with depression as primary and secondary diagnoses. Moreover, mindfulness has been shown to be effective in relapse prevention in depression with an overall risk ratio mean of 0.66 (95\% CI 0.53 to 0.82 , $\mathrm{p}<0.01) .{ }^{20}$ Comorbid disorders such as anxiety have also been shown to be sensitive to mindfulness-based interventions. ${ }^{21}$ Mindfulness has also appeared as a component in Internet-based CBT treatments, but there have been few studies on mindfulness as a stand-alone, digitally distributed treatment for depression. ${ }^{22}$

Research suggests that depression severity is a significant moderating factor in the treatment of depression. There are also indications of a distinct difference between antidepressant medication and placebo in severe depression. Such a difference has not been verified in mild-to-moderate depression, ${ }^{23}$ and that combined treatments with medication and psychotherapy are more effective than single treatments. ${ }^{24}$ These results suggest that baseline depression severity may moderate the response to different variants of treatments. Thus, it is concluded that different treatments distributed digitally can target different subgroups of depression, in terms of severity. For example, Dimidjian et $a l^{7}$ found that among more severely depressed patients, BA was as effective as antidepressant medication, and significantly outperformed cognitive therapy, whereas for the less severely depressed patients, no differential treatment effects were observed. However, in meta-analyses on BA versus cognitive therapy this has not been found. ${ }^{24}$

The advantages as well as the challenges of using mobile phones in CBT treatment have been summarised by Boschen and Casey. ${ }^{25}$ One challenge with using the mobile phone as a platform for psychological treatment is that the user must be able to interact with the programme in an easy way. ${ }^{25}$ In order to attain this simple and fast interaction, it might be easier to target-specific treatment components than entire treatment programmes in smartphone applications. This would make BA and mindfulness, both components in more extensive treatment packages, suitable targets for smartphonebased interventions. Another important feature of mobile technology is the possibility for the therapist to reach the patient outside of the therapy room or when not sitting in front of the computer, and thus create direct incentives for behaviour change in the patient's everyday life. ${ }^{25}$ Therefore, BA is a treatment that could benefit from the use of new mobile technologies (eg, smartphones), even more than mindfulness, by creating direct incentives for BA in patient's everyday life.

In this study, we hypothesised that BA treatment delivered over smartphone would be more effective than mindfulness treatment delivered over smartphone. A meta-analysis by Mazzucchelli $e t a l^{26}$ detected a significant moderate pooled effect size of Hedges' $\mathrm{g}=0.33$ (Cohen's $\mathrm{d}=0.31$ ) when comparing BA with other psychological interventions, such as psychoeducation about depression, problem-solving, assertiveness training and brief interventions. As such, we expected a moderate between-group effect size (Cohen's $\mathrm{d}=0.50^{27}$ ) in this study. We also expected, in line with Dimidjian et $a l_{\mathrm{s}} \mathrm{s}^{7}$ conclusion, that BA would be superior to mindfulness for participants suffering from more severe depression (scored $\geq 10$ on 9-item Patient Health Questionnaire Depression Scale (PHQ-9) and fulfilled the criteria for an ongoing primary diagnosis of major depression of moderate character). Since we did not test the effects of a full MBCT programme but rather a brief version with fewer exercises, the mindfulness application was not hypothesised to be as effective as the BA. In addition, research has shown that depressed individuals, to a greater extent, have deficits in cognitive functioning such as concentration difficulties, distractibility and impairments in memory, as well as problem in engaging in effortful cognitive processes. ${ }^{28-31}$ Therefore, we concluded that the BA intervention would be more suitable for the more severely depressed participants since mindfulness require more cognitive functioning in initial stages, such as the ability to control attention in order to focus on the present moment. ${ }^{32} 33$

The study was based on our previous work on guided Internet-treatment for depression, ${ }^{34}$ but in the current study the treatment content was delivered entirely via the participants' personal smartphones, using recently developed smartphone applications. The aim of this study was to test the effects of two smartphone-delivered treatments: 
one based on BA and the other on mindfulness. Hence, the main question is whether $\mathrm{BA}$ is more effective than mindfulness delivered through a smartphone application. In order to evaluate long-term effects, we also included a 6-month follow-up after the start of the treatment.

\section{METHODS}

\section{Ethics statement}

Written informed consent was obtained from all participants by surface mail before the study started.

\section{Recruitment and selection}

The participants were mainly recruited via mass media and advertisements in large Swedish newspapers. Those who were interested were directed to a web page with information about the study, the treatments being tested and how to participate in the study.

Inclusion criteria for the study were (1) being at least 18 years old, (2) having a point total of $\geq 5$ on PHQ-9, (3) reported unchanged dosage of medication for depression and anxiety during the last month, (4) not being in any concurrent psychological treatment, (5) not suffering from a severe comorbid psychiatric condition that could interfere with the treatment (eg, bipolar disorder or schizophrenia, assessed during a clinical interview), (6) not having other primary medical problems which would need other treatments first hand, (7) not having severe alcohol problems, (8) no assessed risk of being suicidal (see below for details) and (9) suffering from major depression according to the Diagnostic and Statistical Manual of Mental Disorders (DSM)-IV, with at least an episode in partial remission. The diagnosis of MDD was confirmed by a structured interview (see below). In addition, an assessment of suicidal ideation was conducted. The interviews were conducted over telephone by four MSc clinical psychology students. The principal research executive together with the interviewers reviewed all the protocols from the interviews.

Of the 231 individuals who initially expressed interest in the study, 126 completed all the questions in the online screening (22 did not finish the screening and 83 did not begin the screening). Of these, 29 were excluded before the diagnostic interview started. The most common reason for exclusion was an ongoing psychological treatment. Other reasons for exclusion were wrong type of mobile phone (ie, not having access to a smartphone) and score under 5 on the PHQ-9. Thirteen individuals were excluded after the diagnostic interview. The most common reason was that the participant was considered to be in need of another kind of treatment. Eighty-four participants were subsequently included. Before the study started, three participants chose not to participate. Hence, 81 participants were finally included in the data analysis. The reasons for exclusion are specified in the flow chart found in figure 1.

Among the randomised participants, there were $70.3 \%$ women $(n=57)$ and $29.6 \%$ men $(n=24)$. The

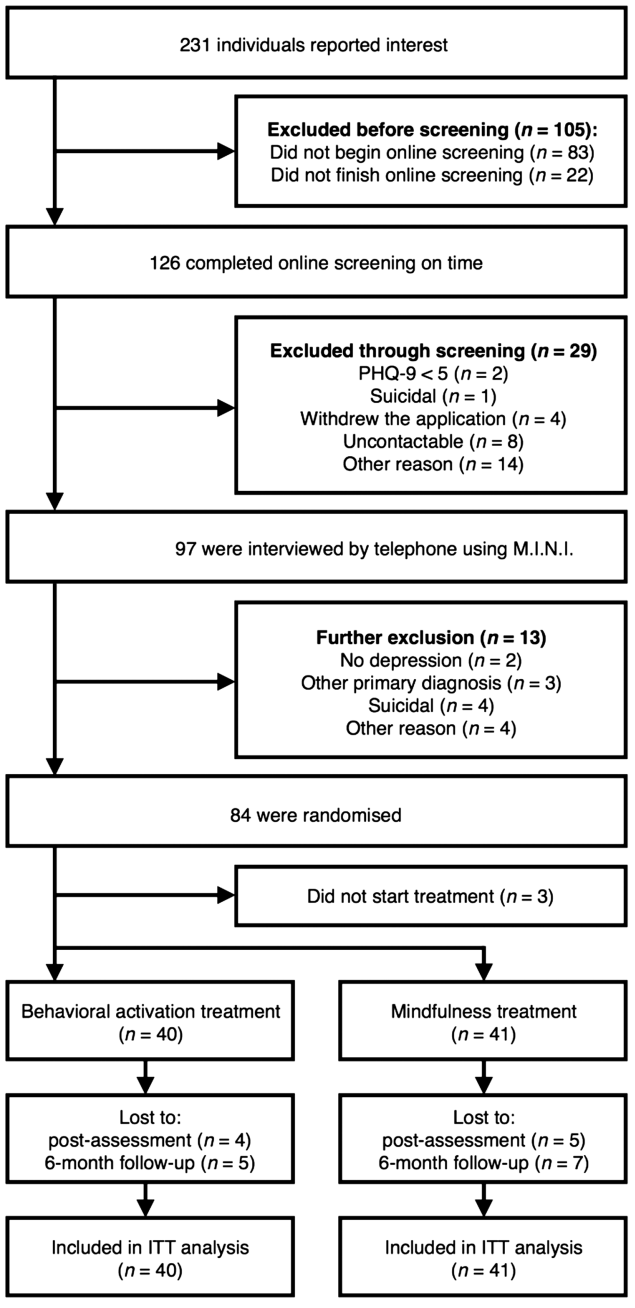

Figure 1 Participant flow chart.

mean age was 36 years $(\mathrm{SD}=10.8)$ ranging from 20 to 61 years. See table 1 for additional demographical data.

\section{Outcome measures}

Primary outcome measures

The primary outcome measures were the Beck Depression Inventory-II (BDI-II ${ }^{35}$ ) and the PHQ-9 ${ }^{36} 37$ that were administered pretreatment, at post-treatment and also 6 months after the treatment had ended. The PHQ-9 was also administered on a weekly basis during the entire treatment phase ( 8 weeks). Hence, there were 3 measurements on the outcome BDI-II and 10 measurements on the outcome PHQ-9 (including pretreatment, post-treatment and 6-month follow-up).

\section{Secondary outcome measures}

In addition to the BDI-II and PHQ-9, the Beck Anxiety Inventory $\left(\mathrm{BAI}^{38}\right)$, the Quality of Life Inventory $\left(\mathrm{QOLI}^{39}{ }^{40}\right.$ ) and the Acceptance and Action Questionnaire (AAQ-II ${ }^{41}$ ) were administered. The AAQ-II was administered on a weekly basis during the entire treatment phase (8 weeks). All other outcome measures were collected at 
Table 1 Demographic description of the participants at randomisation

\begin{tabular}{|c|c|c|c|}
\hline & Behavioural activation $(\mathrm{N}=40)$ & Mindfulness $(\mathrm{N}=41)$ & Total $(\mathrm{N}=81)$ \\
\hline \multicolumn{4}{|l|}{ Age } \\
\hline Mean (SD) & $36.6(10.5)$ & $35.6(11.3)$ & $36.1(10.8)$ \\
\hline Minimum-maximum & $20-59$ & $21-61$ & $20-61$ \\
\hline \multicolumn{4}{|l|}{ Gender } \\
\hline Female & $28(70 \%)$ & $29(70.7 \%)$ & $57(70 \%)$ \\
\hline Male & $12(30 \%)$ & $12(29.3 \%)$ & $24(30 \%)$ \\
\hline \multicolumn{4}{|l|}{ Marital status } \\
\hline Single & $15(37.5 \%)$ & $15(36.6 \%)$ & $30(37 \%)$ \\
\hline Married & $19(47.5 \%)$ & $24(58.6 \%)$ & $43(53.2 \%)$ \\
\hline Divorced/widow/widower & $5(12.5 \%)$ & $1(2.4 \%)$ & $6(7.4 \%)$ \\
\hline Other & $1(2.5 \%)$ & $1(2.4 \%)$ & $2(2.4 \%)$ \\
\hline \multicolumn{4}{|l|}{ Highest educational level } \\
\hline 9-year compulsory school & $1(2.5 \%)$ & $2(4.9 \%)$ & $3(3.8 \%)$ \\
\hline Secondary school & $11(27.5 \%)$ & $14(34.1 \%)$ & $25(30.9 \%)$ \\
\hline College/university & $27(67.5 \%)$ & $24(58.5 \%)$ & $51(63 \%)$ \\
\hline Other & $1(2.5 \%)$ & $1(2.4 \%)$ & $2(2.5 \%)$ \\
\hline \multicolumn{4}{|l|}{ Employment status } \\
\hline Employed/student & $35(87.5 \%)$ & $30(73.2 \%)$ & $65(80.2 \%)$ \\
\hline Unemployed & $3(7.5 \%)$ & $3(7.3 \%)$ & $6(7.4 \%)$ \\
\hline Retired & $0(0 \%)$ & $1(2.4 \%)$ & $1(1.2 \%)$ \\
\hline Other & $2(6.3 \%)$ & $7(17.1 \%)$ & $9(11.1 \%)$ \\
\hline \multicolumn{4}{|l|}{ Type of smartphone } \\
\hline Iphone & $24(60 \%)$ & $23(56.1 \%)$ & $47(58 \%)$ \\
\hline Android & $16(40 \%)$ & $18(43.9 \%)$ & $34(42 \%)$ \\
\hline \multicolumn{4}{|l|}{ Medication } \\
\hline Yes, earlier & $10(25 \%)$ & $13(31.7 \%)$ & $23(28.4 \%)$ \\
\hline Yes, present & $12(30 \%)$ & $14(34.1 \%)$ & $26(32.1 \%)$ \\
\hline None & $18(45 \%)$ & $14(34.1 \%)$ & $32(39.5 \%)$ \\
\hline \multicolumn{4}{|l|}{ Psychological treatment } \\
\hline Yes, earlier & $19(47.5 \%)$ & $23(56.1 \%)$ & $42(51.9 \%)$ \\
\hline None & $21(52.5 \%)$ & $18(43.9 \%)$ & $39(48.1 \%)$ \\
\hline \multicolumn{4}{|l|}{ Experience of self-help literature } \\
\hline Yes & $12(30 \%)$ & $13(31.7 \%)$ & $25(30.9 \%)$ \\
\hline None & $28(70 \%)$ & $28(68.3 \%)$ & $56(69.1 \%)$ \\
\hline \multicolumn{4}{|l|}{ Diagnosis } \\
\hline Depression & $34(85 \%)$ & $32(78 \%)$ & $66(82.5 \%)$ \\
\hline With dysthymia & $22(55 \%)$ & $18(44 \%)$ & $40(49 \%)$ \\
\hline Earlier episodes & $31(77.5 \%)$ & $34(83 \%)$ & $65(80 \%)$ \\
\hline Panic disorder & $1(2.5 \%)$ & $3(7.5 \%)$ & $4(5 \%)$ \\
\hline Social phobia & $6(15 \%)$ & $7(17 \%)$ & $13(16 \%)$ \\
\hline Generalised anxiety disorder & $19(47.5 \%)$ & $10(24.5 \%)$ & $29(36 \%)$ \\
\hline
\end{tabular}

pretreatment, post-treatment and at 6 months after the start of the treatment. Hence, there were 3 measurements on the outcomes BAI and QOLI and 10 measurements on the outcome AAQ-II (including pretreatment, post-treatment and 6-month follow-up). All outcome measures used have been shown to have good psychometric properties, with internal consistencies of at least $\alpha=0.79$. Details of this can be found in the respective references of the outcome questionnaires.

\section{Clinician-administered measures}

Psychiatric diagnoses were assessed at pretreatment, posttreatment and at follow-up 6 months after the start of the treatment, using the Mini-International Neuropsychiatric
Interview (M.I.N.I. ${ }^{42}$ ). The M.I.N.I. is a diagnostic interview that, in contrast to several other diagnostic interviews, is completely structured, making it appropriate for other assessors than experienced psychiatrists. ${ }^{42}$ All interviews were conducted over telephone by the four psychology students described above, which at post-treatment were blind to participants' treatment condition. At the 6-month follow-up, the interviews were conducted by other clinical psychology students who were blind to the participant's condition and the treatment they had been given. Recovery rates were defined as no longer fulfilling the criteria for depression according to M.I.N.I. 


\section{Treatment credibility}

To measure participants' perceived treatment credibility, Borkovec and Nau's Credibility/expectancy scale $(\mathrm{C}-\mathrm{Scale})^{43}$ was used. The C-scale measures the way in which the participants view the logic of the treatment (credibility) and the improvements that can be achieved (expectancy) and includes five items on a 10-point scale. Assessment was made after the first week of treatment.

\section{Administration format of self-report measures}

We used an online platform to administer the BDI-II, PHQ-9, BAI, QOLI, AAQ-II and the C-scale. Previous psychometric research has validated Internet-administration of self-rating scales for depression, quality of life and anxiety. ${ }^{44-46}$

\section{Procedure and design}

For those participants included in the study, the results from the online screening were used as pretreatment assessment. After the recruitment, the participants were allocated using an online randomisation tool (http:// www.random.org), handled by an independent person who was separate from the staff conducting the study.

\section{The interventions}

\section{BA treatment}

An 8-week smartphone-based BA intervention with minimal therapist contact (maximum time of $20 \mathrm{~min}$ per participant and week) was developed by our research group. The intervention consisted of a short web-based psychoeducation, and a step-by-step behaviour programme administered via a smartphone application. The psychoeducation aimed to introduce the participants to the treatment and establish a minimum level of knowledge concerning MDD, touching on topics such as the prevalence of depression, its aetiology and maintenance factors based on operant conditioning, as well as the theoretical basis for BA. The text in the web-based psychoeducation was written specially for the current intervention, but inspired by the BA treatment manuals of Martell et $a l^{47}$ and Lejuez et al. ${ }^{48}$ In all, there were three chapters, totalling 11 pages of text, containing 3893 words.

The smartphone application was built as a native application for Iphone, meaning that the application was coded in a specific programming language (objective C), and as a mobile web application for other smartphones. See figure 2 for a screenshot of the application. A prototype of the smartphone application was tested in a pilot study. ${ }^{49}$ This prototype, however, was not specifically designed for depression interventions. The purpose of the BA application was to make it easy for the participant to remember and register important behaviours in order to increase everyday activation. The application contained a database of 54 behaviours, divided into three different areas for the participant to add to their application. See box 1 for the list of behaviours from the database. The database aimed to provide suggestions,

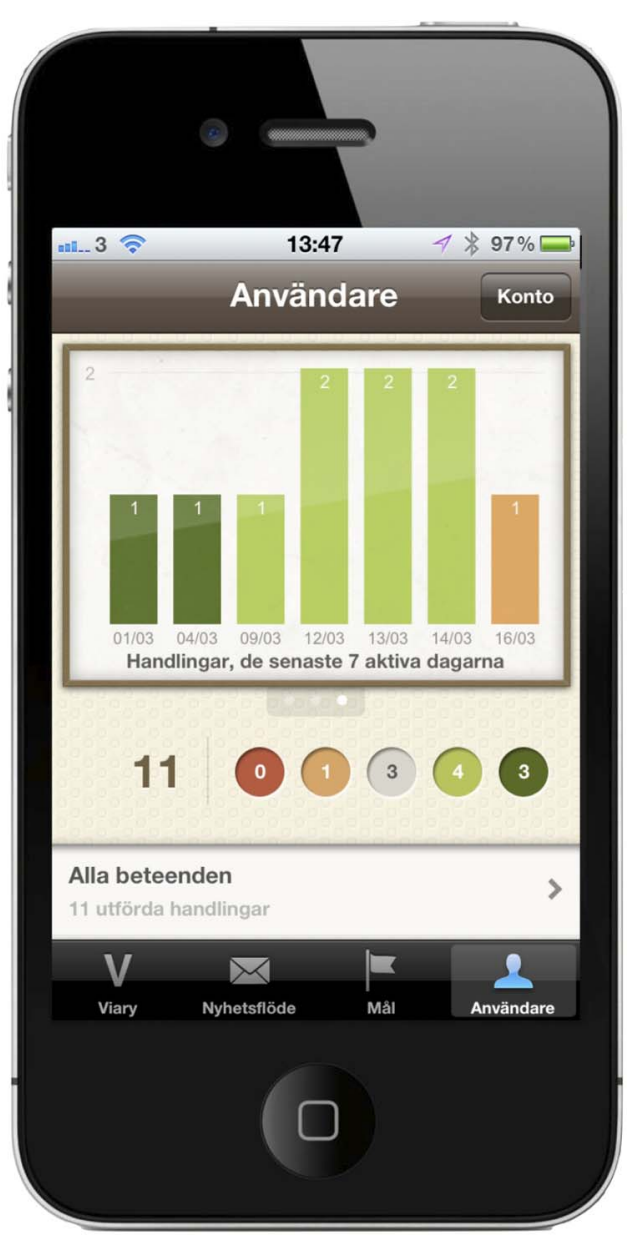

Figure 2 Screenshot of the BA application (the native version).

help and inspiration to get started with the application. Participants were also able to add their own areas and behaviours into the application and start performing and registering these. Through the initial psychoeducation, the participants were advised to add only a few (between 2 and 4) behaviours initially, mainly from the existing database, and to choose behaviours that were easy to perform.

When a behaviour was completed, for example: Get ready in the morning, the participant could register this in the application and add a short reflection. Statistics and summaries of quantitative (ie, behaviour frequency) and qualitative data (ie, reflections) were presented in the application for the participant.

There was also a back-end system where all the quantitative and qualitative data from the participants were accessible from a website for the therapist. From the back-end system, the therapist could send short text messages to the participants via a messaging system, similar to Short Message Service. The messaging system was used by the therapists (described below) to send personal encouraging messages every other or every third day to the participants, as well as weekly general educational messages. The system functioned as a one-way communication, meaning that 


\section{Box 1 List of behaviours in the database}

\section{Everyday structure}

Get out of bed when the bell rings in the morning

Take a shower

Get ready in the morning

Eat breakfast

Read the newspaper

Make a meal plan for each day of the week

Make a shopping list for meals

Buy food for the meals you have planned

Prepare a simple meal

Clean a part of my home

Clean at least $15 \mathrm{~min}$

Washing dishes immediately after a meal

Wash my clothes

Plan my TV viewing from TV schedules

Turn off the TV before 21:00 if I'm still watching TV

Turn off the computer before 21:00 if I'm still on the Internet

Take a brisk walk for $10 \mathrm{~min}$

Log in to my online banking and pay a bill

Entering my weekly activities in my calendar

Social behaviours

Texting a friend and ask what he/she does

Call a friend and ask what the situation is

Take a walk with a friend

Book a meeting with someone in my family

Suggest a coffee with a friend or family member

Suggest a lunch with a friend or family member

Go to the playground with my kids

Bake something with my children

Meet a friend in the evening and ask how your day was

Watching an episode of a TV series with a friend

Go to the movies with a friend

Cooking with someone

New activities

Buy or borrow a book I wanted to read

Read at least 20 min out of a book

Go to a new cafe and coffee

Look up the nearest training centre is

Read on about training online

Post a workout plan for the week

Ask a friend whether he/she wants to come along and train

Spend at least 30 min of physical activity

Listen to a radio programme

Watch a documentary on TV

Eat a good meal out

Write down at least two good things that happened around me

Rent a movie and have a night in

Look up the exhibits that are in my city

See an exhibition at a museum

Look up the concerts that are relevant right now

Go to a concert

Look up the current things happening in my city

Attend a church service

Solve a crossword

Make a Sudoku

Listen to music without doing anything else and focus on what I hear

Go to town and buy something nice for myself the participants were not able to reply to the messages. The participants were also told to write a reflection to summarise every week for their therapist, and send it via email by the end of every treatment week. The participants received personal feedback on their reflection from their therapist via email. No sensitive data, through which the person providing data could be identified, were saved. In addition, all Internet (including the therapists' back-end system) and smartphone activities (including the participants' mobile application) were secured, with Secure Sockets Layer (SSL)-encrypted information.

\section{Mindfulness treatment}

The mindfulness intervention, also an 8-week smartphone-based intervention with a minimal therapist contact (maximum time of $20 \mathrm{~min}$ per participant per week), consisted of a short web-based psychoeducation, and a step-by-step mindfulness practice programme, administered via a smartphone application. The psychoeducation for the mindfulness intervention was equivalent to that of the BA intervention, except that the theoretical basis for mindfulness was presented instead of the theoretical basis for BA. The text was written especially for the current intervention, with inspiration from the self help book The Mindful Way Through Depression by Williams et $a l^{50}{ }^{50}$ In all, there were three chapters, totalling nine pages of text, containing 2927 words.

The smartphone application for Iphone was an established and commercially available application that could be downloaded from the Internet. See figure 3 for a screenshot of the application. For other smartphones, a mobile web application was built especially for the current study with the aim of mimicking the Iphone application. The application consisted of a number of audio tracks with exercises to facilitate the practice of mindfulness. The exercises were of guided and unguided, and in short (3 min) and long ( $30 \mathrm{~min}$ ) format. Through the initial psychoeducation, the participants were advised to begin with short mindfulness exercises, such as a guided $3 \mathrm{~min}$ mindfulness exercise, which was one of the audio tracks in the application.

Since the mindfulness application did not have a communication function, such as the BA application, emails were used to emulate the messaging system in the BA application. Hence, the therapists sent encouraging messages every other, or every third day to the participants, as well as weekly general educational messages via mail. The difference in how the therapists communicated in the mindfulness intervention, compared with the BA intervention, was that the therapists could not give specific feedback on activities or exercises that the participants had performed. Otherwise, the communication was similar (length and type of guided content in the feedback). In addition, the participants given the mindfulness intervention were also asked to write a weekly reflection to summarise their work and thoughts on the 


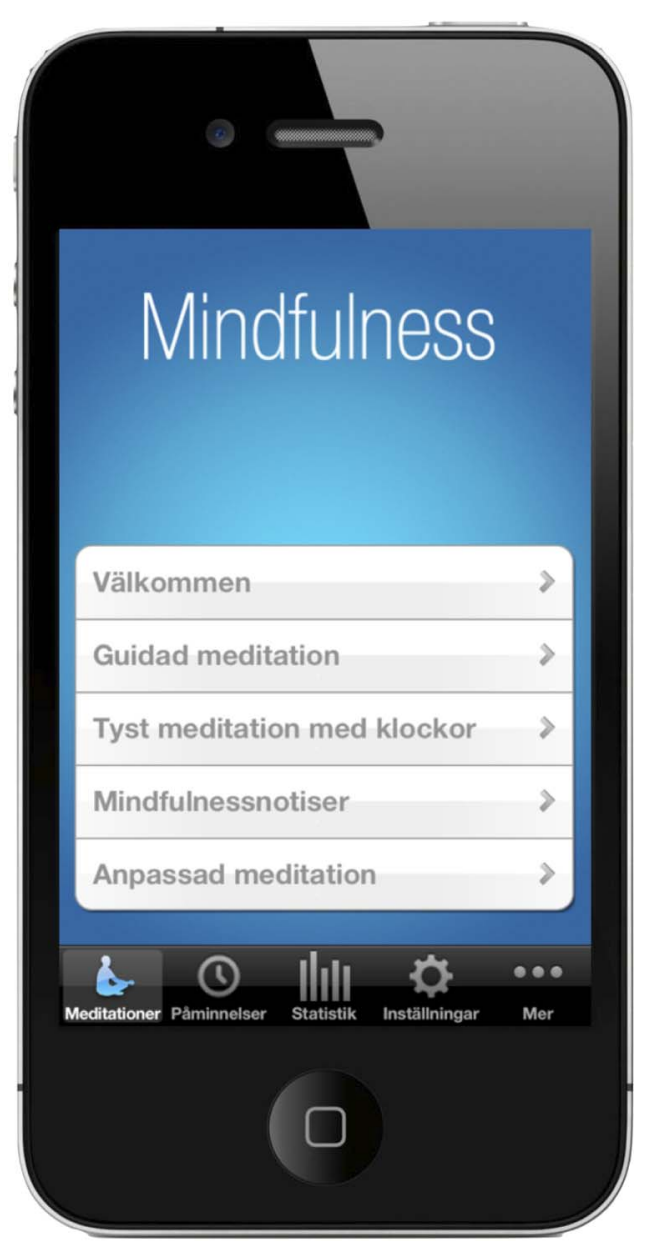

Figure 3 Screenshot of the Mindfulness application (the native version).

current treatment week, and send this reflection to their therapist via email. The participants received personal feedback on their reflection from their therapist.

\section{Therapists}

The therapists were four final-semester students from a 5-year MSc clinical psychologist programme. All therapists had completed their clinical training as well as 16 weeks of practice. Each therapist was responsible for the treatment or 8-10 participants from the BA group and an equal number of participants from the mindfulness group. The therapists were randomly allocated to the participants, with the restriction of not having more than 10 participants from each group. For the entire duration of the study, the therapists received continuous supervision from an experienced psychotherapist with CBT orientation, who had a previous experience of working with a BA treatment manual, as well as mindfulness in depression treatment.

\section{Subgroups based on cut-off scores}

All randomised participants were classified into groups of either high or low severity of depression. These classes were formed based on the cut-off scores on the
PHQ-9. The participants were considered to suffer from higher severity of depression if they scored $\geq 10$ on PHQ-9 and if they fulfilled the criteria for an ongoing primary diagnosis of major depression of moderate character $(n=51)$. Participants not fulfilling these criteria were considered to suffer from lower severity of depression $(n=30)$.

\section{Data analysis}

All the analyses were performed using SPSS V.20 (SPSS, Inc, Chicago, Illinois, USA). Independent $\mathrm{t}$ tests and $\chi^{2}$ tests were used to test for group differences in demographics, pretreatment data and recovery rates. In order to adhere to the intention-to-treat principle, the continuous outcome variables were analysed using mixed effects models, given their ability to handle missing data. ${ }^{51}$ All the analyses used maximum likelihood estimation. Random intercept models were selected for all measures. Differences between the BA treatment and the mindfulness treatment were primarily investigated by modelling interaction effects of group and time. For the PHQ-9 and the AAQ-II, where weekly measures were available, the covariance between the random intercept and slope was not significant, and therefore was not included in the model. Hence, a random intercept model was also used for these measures. Between-group differences at post-treatment were analysed using independent $\mathrm{t}$ tests. Power analysis indicated an $89 \%$ chance of detecting a between-group effect size of $d=0.60$ ( $\alpha$ level=0.05, one tailed). Within-group and between-group effect sizes (Cohen's d) were calculated by dividing the differences in means by the pooled SDs. ${ }^{52}$ This was carried out from premeasurements to postmeasurements, and from premeasurements to the 6-month follow-up data.

\section{RESULTS}

The two groups did not differ significantly on any of the measures at pretreatment $(\mathrm{t}=0.50$ to 0.67 , $\mathrm{df}=79, \mathrm{p}=0.78$ $0.50)$. Also, there was no significant difference in demographic characteristics between the groups according to $\chi^{2}$ analysis $\left(\chi^{2}=0.01\right.$ to $\left.1.03, \mathrm{df}=1, \mathrm{p}=0.22-0.57\right)$. See table 1 for demographical data. See table 2 for all outcome measurements at pretreatment, post-treatment and at 6-month follow-up. The results will be presented in the following order: attrition and adherence, self-report inventories (including effect size) for the whole sample and the subgroups, recovery rates and treatment credibility.

\section{Attrition and adherence}

Of the 84 participants randomised, 3 decided not to participate in the study. Nine of these 81 participants $(11.1 \%)$ did not provide post-treatment data with a distribution of four participants from the BA group and five participants from the mindfulness group. Six of the 81 participants (totalling $7.4 \%$ ) were unreachable for the M.I.N.I. telephone interview and were classified as 


\begin{tabular}{|c|c|c|c|c|c|c|c|}
\hline \multirow[b]{2}{*}{$\begin{array}{l}\text { Outcome } \\
\text { measure }\end{array}$} & \multicolumn{3}{|l|}{ Mean (SD) } & \multicolumn{4}{|c|}{ Effect size, d (95\% Cl) } \\
\hline & Pretreatment & Post-treatment & $\begin{array}{l}\text { 6-month } \\
\text { follow-up }\end{array}$ & $\begin{array}{l}\text { Between-group, } \\
\text { pre-post }\end{array}$ & $\begin{array}{l}\text { Between-group, pre- } \\
\text { 6-month follow-up }\end{array}$ & $\begin{array}{l}\text { Within-group, pre- } \\
\text { post }\end{array}$ & $\begin{array}{l}\text { Within-group, pre- } \\
\text { 6-month follow-up }\end{array}$ \\
\hline \multicolumn{8}{|l|}{ Total } \\
\hline \multicolumn{8}{|l|}{ BDI-II } \\
\hline BA & $23.50(7.85)$ & $10.89(5.92)$ & $12.71(10.56)$ & 0.25 & 0.03 & $1.83(0.27 \text { to } 3.38)^{\star \star}$ & $1.19(-0.87 \text { to } 3.24)^{\star *}$ \\
\hline MF & $24.68(9.47)$ & $12.94(10.18)$ & $13.09(12.24)$ & $(-1.65$ to 2.15$)$ & $(-2.63$ to 2.69$)$ & $1.21(-0.95 \text { to } 3.38)^{\star \star}$ & $1.09(-1.32 \text { to } 3.50)^{\star *}$ \\
\hline \multicolumn{8}{|l|}{ PHQ-9 } \\
\hline $\mathrm{BA}$ & $12.53(4.43)$ & $5.83(3.85)$ & $6.77(5.83)$ & 0.28 & 0.15 & $1.63(0.71 \text { to } 2.56)^{\star \star}$ & $1.14(-0.01 \text { to } 2.28)^{\star \star}$ \\
\hline MF & $13.22(4.81)$ & $7.19(5.84)$ & $7.74(7.33)$ & $(-0.85$ to 1.40$)$ & $(-1.39$ to 1.69$)$ & $1.15(-0.02 \text { to } 2.32)^{\star *}$ & $0.91(-0.44 \text { to } 2.27)^{\star *}$ \\
\hline \multicolumn{8}{|l|}{$\mathrm{BAI}$} \\
\hline BA & $14.60(9.09)$ & $8.81(5.77)$ & $8.34(8.50)$ & 0.06 & 0.01 & $0.76(-0.95 \text { to } 2.47)^{\star \star}$ & $0.72(-1.25 \text { to } 2.69)^{\star \star}$ \\
\hline MF & $13.51(9.31)$ & $9.22(7.68)$ & $8.38(7.48)$ & $(-1.49$ to 1.61$)$ & $(-1.86$ to 1.87$)$ & $0.51(-1.39 \text { to } 2.40)^{\star \star}$ & $0.61(-1.30 \text { to } 2.51)^{\star *}$ \\
\hline \multicolumn{8}{|l|}{ AAQ-II } \\
\hline $\mathrm{BA}$ & $27.28(7.05)$ & $21.22(8.24)$ & $20.09(9.28)$ & 0.22 & 0.10 & $0.80(-0.89 \text { to } 2.50)^{\star \star}$ & $0.89(-0.93 \text { to } 2.72)^{\star *}$ \\
\hline MF & $28.22(7.09)$ & $23.32(10.82)$ & 21.03 (9.68) & $(-1.97$ to 2.41$)$ & $(-2.10$ to 2.31$)$ & $0.56(-1.44 \text { to } 2.54)^{*}$ & $0.87(-1.00 \text { to } 2.74)^{\star *}$ \\
\hline \multicolumn{8}{|l|}{ QOLI } \\
\hline $\mathrm{BA}$ & $-0.45(1.38)$ & $0.92(1.66)$ & $1.15(2.40)$ & 0.05 & 0.01 & $0.91(0.58 \text { to } 1.25)^{\star \star}$ & $0.84(0.41$ to 1.27$) * \star$ \\
\hline MF & $-0.20(1.51)$ & $0.84(1.90)$ & $1.13(2.07)$ & $(-0.36$ to 0.45$)$ & $(-0.53$ to 0.51$)$ & $0.62(0.24 \text { to } 0.99)^{\star \star}$ & $0.75(0.36 \text { to } 1.15)^{\star \star}$ \\
\hline \multicolumn{8}{|l|}{ H-LDep } \\
\hline \multicolumn{8}{|l|}{ BDI-II } \\
\hline $\mathrm{BA}$ & $26.87(7.14)$ & $12.00(6.31)$ & $11.81(10.63)$ & 0.42 & 0.39 & $2.25(0.33 \text { to } 4.18)^{\star \star}$ & $1.72(-0.87 \text { to } 4.31)^{\star \star}$ \\
\hline MF & $28.00(8.61)$ & $15.68(10.76)$ & $16.28(12.71)$ & (-2.09 to 2.93$)$ & $(-2.95$ to 3.73$)$ & $1.62(-0.44 \text { to } 3.67)^{\star *}$ & $1.32(-1.07 \text { to } 3.71)^{\star *}$ \\
\hline \multicolumn{8}{|l|}{ PHQ-9 } \\
\hline BA & 15.52 (3.29) & $6.64(4.42)$ & $6.48(5.59)$ & 0.36 & 0.47 & $2.34(1.23 \text { to } 3.45)^{\star \star}$ & $2.04(0.73 \text { to } 3.35)^{\star *}$ \\
\hline MF & 15.57 (3.35) & $8.60(6.29)$ & $9.60(7.71)$ & $(-1.17$ to 1.90$)$ & $(-1.46 \text { to } 2.40)^{\star}$ & $1.43(0.13 \text { to } 2.74)^{\star \star}$ & $1.05(-0.49 \text { to } 2.58)^{\star \star}$ \\
\hline \multicolumn{8}{|r|}{ (1) } \\
\hline BA & $17.43(9.37)$ & $9.18(6.68)$ & $9.62(8.91)$ & 0.20 & 0.01 & $1.03(-1.30 \text { to } 3.37)^{\star \star}$ & $0.87(-1.77 \text { to } 3.52)^{\star \star}$ \\
\hline MF & 15.57 (9.39) & 10.68 (8.39) & $9.72(7.91)$ & $(-1.94$ to 2.34$)$ & $(-2.36$ to 2.38$)$ & $0.56(-1.80 \text { to } 2.92)^{*}$ & $0.68(-1.62 \text { to } 2.99)^{\star *}$ \\
\hline \multicolumn{8}{|l|}{ AAQ-II } \\
\hline BA & $28.27(7.21)$ & $21.68(8.90)$ & $19.33(9.27)$ & 0.44 & 0.47 & $0.83(-1.47 \text { to } 3.14)^{\star \star}$ & $1.11(-1.28 \text { to } 3.49)^{\star \star}$ \\
\hline MF & $29.04(6.50)$ & 25.87 (10.52) & 23.56 (9.33) & $(-2.30$ to 3.18$)$ & $(-2.16$ to 3.09$)$ & $0.38(-1.90$ to 2.65$)$ & $0.70(-1.40 \text { to } 2.80)^{*}$ \\
\hline \multicolumn{8}{|l|}{ QOLI } \\
\hline BA & $-0.51(1.30)$ & $0.78(1.58)$ & $1.25(2.07)$ & 0.26 & 0.34 & $0.91(0.50 \text { to } 1.33)^{\star \star}$ & $1.05(0.56 \text { to } 1.55)^{\star \star}$ \\
\hline MF & $-0.71(1.18)$ & $0.38(1.58)$ & $0.53(2.23)$ & $(-0.70$ to 0.18$)$ & $(-0.95$ to 0.27$)$ & $0.80(0.44 \text { to } 1.17)^{\star *}$ & $0.72(0.26 \text { to } 1.18)^{\star *}$ \\
\hline \multicolumn{8}{|l|}{$L-L D e p$} \\
\hline \multicolumn{8}{|l|}{ BDI-II } \\
\hline $\mathrm{BA}$ & $18.94(6.47)$ & $9.14(4.96)$ & $14.07(10.71)$ & -0.51 & -1.21 & $1.74(-0.25 \text { to } 3.72)^{\star \star}$ & $0.58(-2.36$ to 3.52$)$ \\
\hline MF & 17.54 (7.09) & $6.73(4.86)$ & $4.22(3.63)$ & $(-2.36$ to 1.34$)$ & $(-4.13 \text { to } 1.71)^{\star}$ & $1.83(-0.54 \text { to } 4.19)^{\star \star}$ & $2.35(-0.03 \text { to } 4.72)^{\star \star}$ \\
\hline \multicolumn{8}{|l|}{ PHQ-9 } \\
\hline BA & $8.47(1.59)$ & $4.57(2.34)$ & $7.21(6.36)$ & -0.23 & -0.98 & $2.06(1.39 \text { to } 2.72)^{\star \star}$ & $0.30(-1.21$ to 1.80$)$ \\
\hline MF & $8.15(3.34)$ & $4.00(2.86)$ & $2.56(1.51)$ & $(-1.20$ to 0.74$)$ & $(-2.68 \text { to } 0.72)^{\star \star}$ & $1.38(0.19 \text { to } 2.59)^{*}$ & $2.13(1.03 \text { to } 3.23)^{\star \star}$ \\
\hline
\end{tabular}




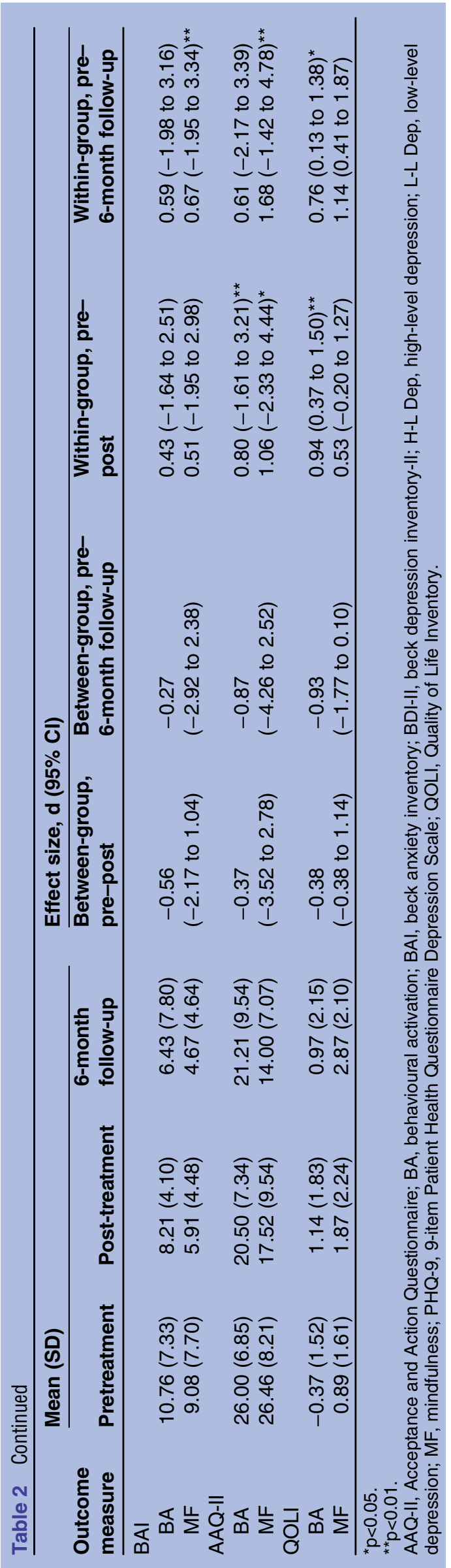

unimproved in the data analysis. In the 6-month follow-up, 69 participants from the two treatment groups (totalling $85.2 \%$ ) provided data on the self-report measures, with a distribution of 35 participants from the BA group and 34 participants from the mindfulness group. Fifty-nine participants $(\mathbf{7 2 . 8 \%})$ were reached for the M.I. N.I. telephone interview. Once again, those unreachable were classified as unimproved in the data analysis.

In a study by Andersson et $a l^{53}$ the number of postings in a discussion group was used as a process factor. Therefore, we defined adherence to treatment as the number of weekly reflections the participants sent to their therapist. In order to be considered as a completed week, at least one reflection had to have been sent to the therapist during that week. Of the 81 participants, $57(70 \%)$ succeeded to adhere to all the 8 weeks. Of these, $25(63 \%)$ were in the BA group and $32(78 \%)$ were in the mindfulness group. No significant difference in adherence was found between the two groups $\left(\chi^{2}(\mathrm{~N}=81, \mathrm{df}=1)=2.35, \mathrm{p}=1.00\right)$. The participants succeeded to adhere to, on an average, 6 weeks $(\mathrm{M}=5.8$, $\mathrm{SD}=2.47)$.

\section{Primary outcome measures}

No significant interaction effects of group and time on the PHQ-9 and the BDI-II were found between the groups, either from pretreatment to post-treatment (PHQ-9 (F $(1,501.47)=0.28, \mathrm{p}=0.60)$; BDI-II $(\mathrm{F}(1,74.11)$ $=0.28, \mathrm{p}=0.60))$, or from pretreatment to the 6 -month follow-up (PHQ-9 $(\mathrm{F}(1,571.49)=0.36, \mathrm{p}=0.55)$; BDI-II $(\mathrm{F}(1,147.96)=0.09, \mathrm{p}=0.77))$. However, as evident from table 2, large within-group effect sizes were found on PHQ-9 and BDI-II, between pretreatment and posttreatment, as well as between pretreatment to the 6-month follow-up. This was the case for the BA treatment and the mindfulness treatment.

\section{Subgroup analyses}

For the participants (total $n=51, B A n=23, M F n=28$ ) suffering from high severity of depression $(\geq 10$ on the PHQ-9 and an ongoing primary diagnosis of major depression of moderate character), a mixed-effects model analysis on the PHQ-9 revealed significant interaction effects of group and time in favour for the BA group from pretreatment to 6-month follow-up, but not on pretreatment to post-treatment. Thus, the results indicated a difference between the BA group and the mindfulness group from pretreatment to 6-month follow-up $(\mathrm{F}(1,362.1)=5.2, \mathrm{p}<0.05)$ for the participants suffering from higher severity of depression. As seen in table 2, the effect size between the groups at 6-month follow-up was moderate (Cohen's $\mathrm{d}=0.47$; CI -1.46 to $2.40)$. No difference between the groups from pretreatment to post-treatment was found.

For the more mildly depressed participants (total $\mathrm{n}=30$, BA $\mathrm{n}=17$, MF $\mathrm{n}=13$ ), there was a significant effect in favour of the mindfulness group from pretreatment to 6-month follow-up on the PHQ-9 (F(1, 69.3)=7.7, 
$\mathrm{p}<.01)$ and the BDI-II $(\mathrm{F}(1,53.60)=6.25, \mathrm{p}<0.05)$. The effect sizes were, as evident from table 2, large (PHQ-9: Cohen's d $=0.98 ; \mathrm{CI}-0.72$ to 2.68; BDI-II: Cohen's $\mathrm{d}=1.21$; CI -1.71 to 4.13 ). No difference between the groups from pretreatment to post-treatment was found.

\section{Secondary outcome measures}

As evident from table 2, no significant interaction effects were found on the secondary measures between the groups, either from pretreatment to post-treatment (BAI $(\mathrm{F}(1,74.05)=1.30, \mathrm{p}=0.26)$; AAQ-II $(\mathrm{F}(1,570.00)=.07$, $\mathrm{p}=0.79)$; QOLI $(\mathrm{F}(1,76.43)=0.1 .06, \mathrm{p}=0.31))$, or from pretreatment to the 6-month follow-up (BAI $(\mathrm{F}(1,147.01)$ $=0.35, \mathrm{p}=0.56)$; AAQ-II $(\mathrm{F}(1,639.00)=0.11, \mathrm{p}=0.74)$; QOLI $(\mathrm{F}(1,148.61)=0.39, \mathrm{p}=0.53))$. Nevertheless, as shown in table 2, medium to large within-group effect sizes were revealed on all secondary outcome measures. This was evident for both groups, and on pretreatment to posttreatment, as well as on pretreatment to the 6-month follow-up.

\section{Recovery rates}

Recovery rates were defined as no longer fulfilling the criteria for depression according to M.I.N.I. There were no significant differences in recovery rates between the groups, either at post-treatment or at the 6-month follow-up. This was the case when analysing the whole sample as well as the subgroups. When analysing the whole sample $(n=81), 73.5 \% \quad(n=25)$ in the BA group recovered at post-treatment, compared with $53.1 \%$ $(\mathrm{n}=17)$ in the mindfulness group $\left(\chi^{2}(\mathrm{~N}=66, \mathrm{df}=1)=2.97\right.$, $\mathrm{p}=0.07)$. At the 6-month follow-up, 30 of 34 participants (88.2\%) from the BA group had recovered, and 26 of 32 participants $(81.3 \%)$ from the mindfulness group had recovered $\left(\chi^{2}(\mathrm{~N}=66, \mathrm{df}=1)=0.63, \mathrm{p}=0.33\right)$.

When analysing only the severely depressed participants, there was a tendency in favour of the BA group. Among the severely depressed participants, $73.9 \%$ $(n=17)$ in the BA group recovered at post-treatment, compared with $50 \%(\mathrm{n}=14)$ in the mindfulness group $\left(\chi^{2} \quad(\mathrm{~N}=51, \quad \mathrm{df}=1)=3.03, \quad \mathrm{p}=0.07\right)$. At the 6-month follow-up, 21 of 23 participants $(91.3 \%)$ from the BA group had recovered, and 22 of 28 participants $(78.6 \%)$ from the mindfulness group had recovered $\left(\chi^{2}(\mathrm{~N}=51\right.$, $\mathrm{df}=1)=1.55, \mathrm{p}=0.20)$.

Among the less severe depressed participants, $82.4 \%$ $(n=14)$ in the BA group recovered at post-treatment, compared with $92.3 \%(\mathrm{n}=12)$ in the mindfulness group $\left(\chi^{2} \quad(\mathrm{~N}=30, \mathrm{df}=1)=0.63, \mathrm{p}=0.41\right)$. At the 6-month follow-up, the number of participants from the BA group who had recovered remained the same as in the postmeasurement $(n=14)$. In the mindfulness group, all the participants $(n=13)$ from the mindfulness group had recovered at the 6-month follow-up $\left(\chi^{2} \quad(\mathrm{~N}=30, \mathrm{df}=1)\right.$ $=2.549, \mathrm{p}=0.17)$; however, no significant differences in recovery rates between the groups was found when analysing only the less severe depressed participants.
Treatment credibility and therapist time

Treatment credibility ratings (C-scale) after 1 week of treatment showed that participants in both groups rated their respective treatment as credible. Of a possible total of 50 , the average scores were $31.9(\mathrm{SD}=7.1)$ for the $\mathrm{BA}$ group and $32.1 \quad(\mathrm{SD}=7.8)$ for the mindfulness group. There was no significant difference in treatment credibility between the two groups ( $\mathrm{t}(78)=0.12, \mathrm{p}=0.90$ ). Furthermore, treatment credibility did not correlate significantly with any of the outcome measures, either for all participants combined $(\mathrm{r}=0.13, \mathrm{p}=0.27)$, for the BA group $(\mathrm{r}=0.01, \mathrm{p}=0.92)$ or for the mindfulness group $(\mathrm{r}=0.23, \mathrm{p}=0.18)$.

The therapist time per participant per week varied depending on whether the participant had sent a reflection or not. The therapists reported a span between 2 and $18 \mathrm{~min} /$ week and participant. The therapists reported that the time they spent did not differ between the two treatment groups.

\section{DISCUSSION}

The overall aim of this study was to evaluate and compare the effects of two smartphone-delivered treatments for people suffering from mild-to-moderate major depression: one based on BA and the other on mindfulness. Hence, the main question was whether BA is more effective than mindfulness delivered through a smartphone application. We hypothesised that BA treatment delivered via smartphone would be more effective than mindfulness treatment delivered via smartphone. We also expected that BA would be superior to mindfulness for participants suffering from more severe depression. When analysing the whole sample as one entity, the result showed that the two interventions did not differ significantly from one another, either from pretreatment to post-treatment or from pretreatment to the 6-month follow-up on any of the outcome measures. Also, there were no significant differences in recovery rates between the groups, either at post-treatment or at the 6-month follow-up.

This study also explored how different levels of initial depression severity could moderate response to the different interventions. All randomised participants were classified into either high or low severity of depression based on the cut-off scores on the PHQ-9 and whether they fulfilled the criteria for an ongoing primary diagnosis of major depression. For participants with higher severity of depression, the treatment based on BA was superior to the treatment based on mindfulness, as measured with PHQ-9. In contrast, for participants with lower initial severity, the treatment based on mindfulness was more effective than the treatment based on $\mathrm{BA}$, as measured with PHQ-9 and BDI-II.

The result from the analysis of the higher severity participants is in line with Dimidjian $e t a l \mathrm{~s}^{7}$ finding. In contrast to the meta-analysis by Cuijpers et al, ${ }^{24}$ Dimidjian et $a l^{7}$ found that $\mathrm{BA}$ was comparable in efficacy to 
antidepressant medication, and more efficacious than cognitive therapy, but only among those patients who were more severely depressed. Since it is known that depressed individuals, to a greater extent, have concentration difficulties, distractibility and problems in engaging in effortful cognitive processes, ${ }^{28-31}$ Beck et $a \vec{l}^{4}$ have long suggested that therapists should focus on behavioural strategies early in treatment when patients are more depressed and return to that emphasis later if patients start to worsen. We expected that the BA intervention would be more suitable for the more severely depressed participants since mindfulness require more cognitive functioning in initial stages, such as the ability to control attention in order to focus on the present moment. ${ }^{32} 33$

The result from the analysis of the less severely depressed participants was unexpected to us. Although there is only initial evidence that mindfulness treatment is effective for acute or severely depressed patients, ${ }^{55} 56$ mindfulness has proven to be effective for relapse prevention of recurrent depression. ${ }^{20} 57 \quad 58$ A possible explanation of the results could be that there was a difference between the two treatment groups, although not significant, in the number of participants who were suffering from major depression. In the BA group, $64.7 \%$ $(n=11)$ were diagnosed with major depression in the initial screening, compared with $30.8 \% \quad(n=4)$ in the mindfulness group $\left(\chi^{2}(\mathrm{~N}=30, \mathrm{df}=1)=3.39, \mathrm{p}=0.07\right)$.

Moreover, the results showed significant improvements from pretreatment to post-treatment on the primary outcome measures in both treatment conditions with large within-group effect sizes and large recovery rates, comparable to other depression treatments. ${ }^{59} 60$ This might indicate that the smartphone format used in this study could work well for a depressed population. However, a replication with a waiting list group should be conducted to rule out the possibility that the effects occurred due to natural recovery.

\section{Limitations}

There are a number of limitations that need to be mentioned. The first is that no waiting list group was included. Although our main research question was to assess whether BA is more effective than mindfulness delivered via smartphone, a control group given no intervention would have yielded a more clear result.

A second limitation is that the study was underpowered. Thus, it is difficult to detect significant overall differences between the two smartphone treatments, even if significant interaction effects were found when using mixed-effects model with PHQ-9 in the subgroup analyses. A post hoc power analysis revealed that a sample of 393 participants was required to detect small between-group effects. We did not expect that the mindfulness treatment would be as effective and powered the trial as if a moderate between-group effect would be found.
A third limitation was that the participants were recruited nationally through mass media and advertisements. Thus, we cannot be sure that this treatment would work in a clinical setting, for example, an outpatient psychiatric facility. However, the mean depression severity as measured by the BDI-II at intake $(\mathrm{M}=24.10)$ is rather close to the limit of 29, proposed for defining severe depression, ${ }^{35}$ meaning that the depression severity in this study was comparable to an outpatient psychiatric population.

Fourth, we recruited a broad range of participants, with regard to severity of depression (a minimum of 8 and a maximum of 44 on BDI-II at intake). This makes it difficult to target a specific group for which the treatments would be most effective. Nevertheless, a subgroup analysis showed that the participants with higher severity of depression responded significantly better to the BA than to the treatment based on mindfulness, whereas the treatment based on mindfulness worked significantly better than the treatment based on BA for the participants with lower initial depression severity. Additionally, it can be argued that these broad inclusion criteria reflect a real population (ie, an outpatient psychiatric population) of individuals with depressive disorders. However, this contributed to power limitations as well.

A fifth related concern was the large number of participants that had college-level or university-level education $(65.5 \%)$. This might compromise the generalisability of the results, since it is possible that guided self-help is especially well suited for educated patients. However, there are data indicating that $50 \%$ of patients seeking psychotherapy have some college education ${ }^{61}$ and that educated patients may be more inclined to seek help for mental health problems in general. ${ }^{62}$

\section{Conclusion}

Some clinical implications of this study are discussed as follows. Owing to the need for simple and fast interaction with the treatment programme, singular treatment components such as BA and mindfulness might be a better target for smartphone applications than entire multicomponent treatment packages. At the same time, there is a need for guided self-help treatments distributed digitally that can reach out to more patients. This study is one of the first to test a treatment for depression, administered via smartphone. The large within-group effects on the primary outcome measures, as well as the large recovery rates for both groups, are comparable to other depression treatments and indicate that this smartphone format with a small amount of text and minimal therapist support might work well for a depressed population. However, as aforementioned, a replication with a waiting list group should be conducted to rule out that the effects occurred due to natural recovery.

Moreover, this study also shows that BA might work better for a more severely depressed population, whereas mindfulness might work better for people suffering from light depression. These results suggest that 
different treatments distributed digitally can target different subgroups of depressed patients in terms of severity. However, more studies are needed to strengthen this hypothesis before any conclusions can be drawn.

From a broader perspective, we believe that smartphones will be integrated even further in society since they are already socially accepted and come at relatively low costs considering their functionalities, ${ }^{25}$ and therefore may serve an important role in healthcare. Therefore these results, showing that mild-to-moderate major depression can be treated effectively by means of a supported smartphone application, might be important in making depression treatment and other psychological treatments more assimilated into people's daily life. As suggested by Ly et al, ${ }^{49}$ the smartphone format might also help increasing patients' awareness of being in treatment, even in everyday settings, and therefore better help patients create direct incentives for treatment-related activities in their everyday life. ${ }^{49}$ Using smartphones to distribute psychological treatment might also help making it possible to reach out with psychological therapy to a broader group of people, since their use attracts no attention, ${ }^{25}$ allowing users to interact with a device without fear of judgement or stigma. Lastly, psychological treatments distributed via smartphones are not only relevant for Swedish conditions but also for the developing countries of the world, which increasingly are empowered by mobile phones with Internet connection.

This study might pave the way for a broad range of other trials conducted via smartphones, self-help interventions and face-to-face treatments with the smartphone as an adjunct tool. We believe that a substantial part of Internet-based interventions in the future will be executed through smartphones or at least supported by smartphones. Further studies should focus on both formats, as well as expanding the treatment platform to other psychological disorders.

Contributors KHL developed the application. KHL also participated in the drafting of the treatment manuals, and participated in the analysis and interpretation of data. GA participated in the conception of the study and its design. GA also participated in the drafting of the treatment manuals, analysis and interpretation of data and performed statistical analysis. PC participated in the conception of the study and its design. RJ participated in analysis and interpretation of data, and performed statistical analysis. AT, LJ, SM and TW participated in the drafting of treatment manuals and performed the treatments. KHL and GA drafted the current manuscript. PC and RJ participated in revision of the current manuscript. All authors read and approved the final manuscript.

Funding The Swedish Research Council sponsored this study with funding 2011-2476.

Competing interests A related version of the behavioural activation application is currently developed for the open market by $\mathrm{KHL}$.

Ethics approval The study was approved by the Regional Ethics Board of Linköping, Sweden.

Provenance and peer review Not commissioned; externally peer reviewed.

Data sharing statement Additional unpublished data from the study include answers from the Trimbos and Institute of Medical Technology Assessment Cost Questionnaire for Psychiatry (TIC-P), which is used to measure cost data from a psychological treatment. These extra data are available by emailing kien.hoa.ly@liu.se

Open Access This is an Open Access article distributed in accordance with the Creative Commons Attribution Non Commercial (CC BY-NC 3.0) license, which permits others to distribute, remix, adapt, build upon this work noncommercially, and license their derivative works on different terms, provided the original work is properly cited and the use is non-commercial. See: http:// creativecommons.org/licenses/by-nc/3.0/

\section{REFERENCES}

1. Ebmeier K, Donaghey C, Steele J. Recent developments and current controversies in depression. Lancet 2006;367:153-67.

2. Smit F, Cuijpers $P$, Oostenbrink J, et al. Costs of nine common mental disorders: implications for curative and preventive psychiatry. $J$ Ment Health Policy Econ 2006;9:193-200.

3. Cuijpers $P$, van Straten A, Andersson G, et al. Psychotherapy for depression in adults: a meta-analysis of comparative outcome studies. J Consult Clin Psychol 2008;76:909-22.

4. Cuijpers $P$, van Straten A, Warmerdam L. Behavioral activation treatments of depression: a meta-analysis. Clin Psychol Rev 2007;27:318-26.

5. Dimidjian S, Barrera M, Martell C, et al. The origins and current status of behavioral activation treatments for depression. Annu Rev Clin Psychol 2011;7:1-38.

6. Jacobson N, Dobson K, Truax $\mathrm{P}$, et al. A component analysis of cognitive-behavioral treatment for depression. J Consult Clin Psychol 1996;64:295-304.

7. Dimidjian S, Hollon SD, Dobson KS, et al. Randomized trial of behavioral activation, cognitive therapy, and antidepressant medication in the acute treatment of adults with major depression. J Consult Clin Psychol 2006;74:658-70.

8. Andrews G, Cuijpers P, Craske MG, et al. Computer therapy for the anxiety and depressive disorders is effective, acceptable and practical health care: a meta-analysis. PLOS ONE 2010;5:e13196.

9. Cuijpers $P$, Donker T, van Straten A, et al. Is guided self-help as effective as face-to-face psychotherapy for depression and anxiety disorders? A systematic review and meta-analysis of comparative outcome studies. Psychol Med 2010;40:1943-57.

10. Carlbring $P$, Hagglund $M$, Luthstrom A, et al. Internet-based behavioral activation and acceptance-based treatment for depression: a randomized controlled trial. J Affect Disord 2013;148:331-7.

11. Andersson $\mathrm{G}$. Using the Internet to provide cognitive behaviour therapy. Behav Res Ther 2009;47:175-80.

12. Rizvi SL, Dimeff LA, Skutch J, et al. A pilot study of the DBT coach: an interactive mobile phone application for individuals with borderline personality disorder and substance use disorder. Behav Ther 2011;42:589-600.

13. Watts S, Mackenzie A, Thomas C, et al. CBT for depression: a pilot RCT comparing mobile phone vs. computer. BMC Psychiatry 2013;13:49.

14. Segal ZV, Williams JMG. Mindfulness-based cognitive therapy for depression. Guilford Press, 2012.

15. Linehan M. Cognitive-behavioral treatment of borderline personality disorder. The Guilford Press, 1993.

16. Hayes SC, Strosahl KD, Wilson KG. Acceptance and commitment therapy: an experiential approach to behavior change. Guilford Press New York, 2003.

17. Cash $\mathrm{M}$, Whittingham $\mathrm{K}$. What facets of mindfulness contribute to psychological well-being and depressive, anxious, and stress-related symptomatology? Mindfulness 2010;1:177-82.

18. Brown KW, Ryan RM. The benefits of being present: mindfulness and its role in psychological well-being. J Pers Soc Psychol 2003;84:822-48.

19. Hofmann SG, Sawyer AT, Witt AA, et al. The effect of mindfulness-based therapy on anxiety and depression: a meta-analytic review. J Consult Clin Psychol 2010;78:169-83.

20. Piet J, Hougaard E. The effect of mindfulness-based cognitive therapy for prevention of relapse in recurrent major depressive disorder: a systematic review and meta-analysis. Clin Psychol Rev 2011;31:1032-40.

21. Hofmann SG, Sawyer AT, Witt AA, et al. The effect of mindfulnessbased therapy on anxiety and depression: a meta-analytic review. $J$ Consult Clin Psychol 2010;78:169.

22. Ljotsson $B$, Hedman $E$, Lindfors $P$, et al. Long-term follow-up of internet-delivered exposure and mindfulness based treatment for irritable bowel syndrome. Behav Res Ther 2011;49:58-61. 
23. Fournier JC, DeRubeis RJ, Hollon SD, et al. Antidepressant drug effects and depression severity: a patient-level meta-analysis. JAMA 2010;303:47-53.

24. Cuijpers P, Andersson G, Donker T, et al. Psychological treatment of depression: results of a series of meta-analyses. Nord $J$ Psychiatry 2011;65:354-64.

25. Boschen M, Casey L. The use of mobile telephones as adjuncts to cognitive behavioral psychotherapy. Prof Psychol Res Pract 2008;39:546-52.

26. Mazzucchelli T, Kane R, Rees C. Behavioral activation treatments for depression in adults: a meta-analysis and review. Clin Psychol 2009;16:383-411.

27. Cohen J. Statistical power analysis. Curr Dir Psychol Sci 1992;1:98-101.

28. Clak DA, Beck AT. Scientific foundations of cognitive theory and therapy of depression. Wiley, 1999.

29. Gotlib IH, Joormann J. Cognition and depression: current status and future directions. Annu Rev Clin Psychol 2010;6:285.

30. Ellis HC, Ashbrook PW. Resource allocation model of the effects of depressed mood states on memory. Affect Cogn Soc Behav 1988:25-43.

31. Watts FN, Sharrock R. Description and measurement of concentration problems in depressed patients. Psychol Med 1985;15:317-26.

32. Bishop SR. What do we really know about mindfulness-based stress reduction? Psychosom Med 2002;64:71-83.

33. Tang $\mathrm{Y}-\mathrm{Y}$, Posner MI. Attention training and attention state training. Trends Cogn Sci 2009;13:222-7.

34. Andersson G, Bergstrom J, Hollandare F, et al. Internet-based self-help for depression: randomised controlled trial. $\mathrm{Br} J$ Psychiatry 2005;187:456-61.

35. Beck AT, Steer RA, Brown BK. Beck Depression Inventory Manual, San Antonio, TX: Psychological Corporation, 1996.

36. Titov N, Dear BF, McMillan D, et al. Psychometric comparison of the PHQ-9 and BDI-II for measuring response during treatment of depression. Cogn Behav Ther 2011:40:126-36.

37. Kroenke K, Spitzer R, Williams J. The PHQ-9: validity of a brief depression severity measure. J Gen Intern Med 2001;16:606-13.

38. Beck A, Epstein N, Brown G, et al. An inventory for measuring clinical anxiety: psychometric properties. J Consult Clin Psychol 1988;56:893-97.

39. Lindner $P$, Andersson $G$, Ost LG, et al. Validation of the Internet-administered Quality of Life Inventory (QOLI) in different psychiatric conditions. Cogn Behav Ther 2013;42:315-27.

40. Frisch M, Cornell J, Villanueva M. Clinical validation of the quality of life inventory: a measure of life satisfaction for use in treatment planning and outcome assessment. Psychol Assess 1992;4:92-101.

41. Hayes S, Strosahl K, Bunting K, et al. What is acceptance and commitment therapy? A Practical Guide to Acceptance and Commitment Therapy. New York, NY: Springer-Verlag, 2004:1-30.

42. Sheehan DV, Lecrubier $\mathrm{Y}$, Sheehan $\mathrm{KH}$, et al. The Mini-Internationa Neuropsychiatric Interview (M.I.N.I.): the development and validation of a structured diagnostic psychiatric interview for DSM-IV and ICD-10. J Clin Psychiatry 1998;59(Suppl 20):22-33. quiz 34-57.

43. Borkovec TD, Nau SD. Credibility of analogue therapy rationales. J Behav Ther Exp Psychiatry 1972;3:257-60.
44. Carlbring $\mathrm{P}$, Brunt S, Bohman S, et al. Internet vs. paper and pencil administration of questionnaires commonly used in panic/ agoraphobia research. Comput Hum Behav 2007;23:1421-34.

45. Hedman E, Ljótsson B, Rück $\mathrm{C}$, et al. Internet administration of self-report measures commonly used in research on social anxiety disorder: a psychometric evaluation. Comput Hum Behav 2010;26:736-40.

46. Hollandare F, Andersson G, Engstrom I. A comparison of psychometric properties between internet and paper versions of two depression instruments (BDI-II and MADRS-S) administered to clinic patients. J Med Internet Res 2010;12:e49.

47. Martell CR, Addis ME, Jacobson NS. Depression in context: strategies for guided action. WW Norton \& Co, 2001.

48. Lejuez CW, Hopko DR, Hopko SD. A brief behavioral activation treatment for depression treatment manual. Behav Modif 2001;25:255-86.

49. Ly K, Dahl J, Carlbring P, et al. Development and initial evaluation of a smartphone application based on acceptance and commitment therapy. SpringerPlus 2012;1:11.

50. Williams JMG, Teasdale JD, Segal ZV. The mindful way through depression: freeing yourself from chronic unhappiness. The Guilford Press, 2007.

51. Gueorguieva R, Krystal JH. Move over ANOVA: progress in analyzing repeated-measures data and its reflection in papers published in the Archives of General Psychiatry. Arch Gen Psychiatry 2004;61:310-17.

52. Borenstein M, Hedges LV, Higgins JP, et al. Introduction to meta-analysis. Wiley, 2011.

53. Andersson $\mathrm{G}$, Bergstr $\sqrt{ } \partial \mathrm{m} \mathrm{J}$, Holl $\sqrt{ } \S$ ndare $\mathrm{F}$, et al. Delivering cognitive behavioural therapy for mild to moderate depression via the Internet: predicting outcome at 6-month follow-up. Verhaltenstherapie 2004;14:185-89.

54. Beck AT. Cognitive therapy of depression. The Guilford Press, 1979.

55. Manicavasgar V, Parker G, Perich T. Mindfulness-based cognitive therapy vs cognitive behaviour therapy as a treatment for non-melancholic depression. J Affect Disord 2011;130:138-44.

56. Kenny MA, Williams JM. Treatment-resistant depressed patients show a good response to mindfulness-based cognitive therapy. Behav Res Ther 2007;45:617-25.

57. Psykologisk behandling vid depression: teorier, terapimetoder och forskning A1-Andersson, Gerhard Y1-2012.

58. Andersson G. Psykologisk behandling vid depression: teorier, terapimetoder och forskning, 2012.

59. Barak A, Hen L, Boniel-Nissim M, et al. A comprehensive review and a meta-analysis of the effectiveness of internet-based psychotherapeutic interventions. J Technol Hum Serv 2008;26:109-60.

60. Hedman E, Ljótsson B, Kaldo V, et al. Effectiveness of Internet-based cognitive behaviour therapy for depression in routine psychiatric care. J Affect Disord 2013. In press.

61. Vessey JT, Howard KI. Who seeks psychotherapy? Psychotherapy 1993;30:546.

62. Howard KI, Cornille TA, Lyons JS, et al. Patterns of mental health service utilization. Arch Gen Psychiatry 1996;53:696-703. 